\title{
A RECEPÇÃO ESTÉTICA DOS MONUMENTOS CULTURAIS MSSIONEROSE DA ARIE BARROCA GUARANI NO SÍTIO DE SÃO MGUEL, RIO GRANDE DO SUL
}

João Batista Neto, Prof. Msc.

jbneto@usp.br

\section{Resumo}

Essa comunicação trata da nossa investigação no doutorado sobre a Recepção Estética dos monumentos culturais missioneiros junto aos visitantes das ruinas das Reduçoes Jesuíticas dos Guaranis. O objeto de análise é o sitio de São Miguel das Missões, no Rio Grande do Sul, que envolve o Museu das Missões e foi tombado como Patrimônio Cultural da Humanidade.

\begin{abstract}
This communication is about our doctorate investigation about the Aesthetic Reception of the missioners cultural monuments towards the visitors of the ruins in the Guarani Indians' Jesuits Reductions. The object of analysis is the São Miguel das Missões site in Rio Grande do Sul, which involves the Missions Museum and was classified as a Cultural Patrimony of Mankind.
\end{abstract}

\section{Introdução}

Localizadas no Brasil, Paraguai e Argentina, os 30 povoados missioneiros formaram uma sociedade diferenciada na América Hispânica. A maneira como os índios guaranis foram conduzidos a entrarem na estrutura da sociedade colonial foi o fator diferencial. Segundo Hobsbawn (1979), o antigo Paraguai foi a única área da América Latina onde os índios resistiram ao estabelecimento do elemento europeu de forma efetiva, em grande escala, devido à ação original dos inacianos. Nesta condução, eles estruturaram, durante 150 anos, um sistema de reduções que serviram para impedir o avanço luso na região platina, ao mesmo tempo que consolidavam o catolicismo como a religião dos índios.

A primeira metade do século XVI foi a época da implantação do modelo reducional, das migrações dos povoados, das guerras contra os mamelucos paulistas e os índios inimigos ao modelo. Termina com a derrota dos bandeirantes em 1641, marco divisor, entre este $1^{\circ}$ ciclo missioneiro e o $2^{\circ}$, época da consolidação dos povoados e do auge civilizatório das Reduções Jesuíticas dos Guaranis ${ }^{1}$, até a expulsão em $1768^{2}$.

\footnotetext{
${ }^{1}$ Missão ou Redução? Utilizamos o termo redução por entendermos que o termo missão, em seu sentido restrito, é o sinônimo de ação, que até hoje é realizada pelos padres católicos em suas peregrinações pelo mundo. Redução é o povoamento indígena estável, assistido por Jesuítas, como a experiência guaranítica. " $L a$ definición más simple de una Reducción, dada en el Diccionario de la Lengua Española de la Real Academia Española, es la siguiente: "Pueblo de indios convertidos al cristianismo", ("A definição mais simples de uma Redução, dada no
} 
Neste processo de transculturação ${ }^{3}$, o indígena não se transformou num típico europeu. Manteve consigo durante a vigência do modelo reducional vários traços culturais guaranis, como sua língua, seu artesanato em cerâmica, utensílios ósseos e líticos, objetos em madeira e fibras vegetais, relações de solidariedade e reciprocidade, atividades guerreiras, a caça, a pesca, a coleta de alimentos e algumas crenças reinterpretadas num sincretismo religioso com a religião cristã. E apreendeu do mundo europeu a escrita, novas tecnologias (metalurgia, arquitetura, olaria, etc...) organização política em cabildos, respeito a uma monarquia absoluta, a transformação em guardiões da fronteira, a pecuária, o cultivo da erva mate, um comércio restrito e um novo modo de vida, baseado nos preceitos cristãos da época. Este (...) "complexo fenômeno de contato cultural e de transferência de tecnologia, de aceitação ou resistência a certos padrões culturais europens on permanencia de traços típicos da cultura guarani, caracteriza bem a complexidade das relaçöes sociais que se estabeleceram" (Kern, 1988, p. 07).

Apesar das divergências entre vários estudiosos, entendemos que o estilo de arte manifestado nessa sociedade foi o Barroco Guarani ${ }^{4}$. Nas reduções, quase todas as manifestações artísticas foram realizadas nas suas oficinas, com destaque para a música. Visava sobretudo a evangelização dos catecúmenos e

Dicionário da Língua Espanhola da Real Academia Espanhola, é a seguinte: "Povoado de índios convertidos ao cristianismo") (McNASPY, 1987, p. 11). A origem da palavra redução vem do latim reductionis, ato ou efeito de reduzir, significava "reconduzirr", "converter". Num primeiro momento, o jesuita convertia, submetia o guarani à fé católica. Para isso, procurou aldeá-lo, basicamente, com o objetivo de conversão" (QUEVEDO, 1993, p. 100). Além da palavra redução, será muito empregada a palavra povoado, ambas no sentido de um espaço apropriado e construído. ${ }^{2}$ Esta divisão da história das Reduções Jesuíticas dos Guaranis realizamos na nossa dissertação de Mestrado (BATISTA NeTO, 2003, pg. 19).

3 Ao invés de adotarmos termos como "aculturação", prefere-se o termo "Transculturação", conceito elaborado pelo pesquisador cubano Fernando ORTIZ, no seu livro El Contrapunteo del tabaco y el azucar, utilizado por críticos de arte como Angel RÁMA, que demonstra a passagem de valores culturais entre duas culturas. (apud GONÇALVES, 1994). Trata-se de dizer que no encontro entre essas duas culturas ocorre um processo em que ambas as partes acabam modificadas. É uma via de mão dupla, no qual emerge uma nova realidade.

${ }^{4}$ Mas podemos chamar este Barroco de Guarani? Aqui temos outro grande problema de definição. Infelizmente, a evolução histórica de cada estilo de arte é uma dança de avanços e retrocessos através de regiões e épocas. Ainda mais quando se trata do Barroco, primeiro estilo de arte de escala planetária, onde cada região implantou a sua marca. Chamar este Barroco de Hispano-Guarani, como fez Josephina PLA, não contempla os mestres jesuítas não-espanhóis que viveram nas reduções, como o tirolês Florian Paucke, o italiano Domenico Zipoli ou o francês Luis Verger. Chamá-lo de Barroco Guarani, como pretende MC NASPY, parecenos muito mais condizente com aquela época. "Hablar del barroco con la calificación de "Guarani”" obliga a renovar el concepto de Barroco Americano, como manifestación distinta, aunque planteado en términos autóctonos, de indudable legitimidad en cuanto a su idiosincrasia distintiva" ("Falar do barroco com a qualificacão de "Guarani" obriga a renovar o conceito de Barroco Americano, como manifestação distinta, ainda que planejada em termos autóctones, de indubitável legitimidade enquanto a sua idiosincrasia distintiva") (ALEXANDER, 1984, p. 181). Mas, com bem lembra MELIÁ, devemos esclarecer que esse estilo se refere a um período de 150 anos de dominação jesuítica, em que houveram diversas influências de diferentes regiões, épocas e mestres europeus, não devendo estar solidificado como um bloco de mármore intocável, sem conhecer tendências, correntes ou tempo (apud SUSTERSIC, 1995, p. 240). 
produziam obras para o culto com o objetivo claro de combater o que era emtendido pelo jesuíta como ócio (Escobar, 1980).

Apesar da importância geopolítica das reduções e militar dos índios missioneiros, a Corte Espanhola buscou o entendimento diplomático com os portugueses sobre os limites territoriais das duas metrópoles no cone sul. O Tratado de Madri, de 1750, estabeleceu novos limites entre as possessões de Portugal e Espanha, determinando a troca da Colônia de Sacramento pelos Sete Povos das Missões, no atual Rio Grande do Sul, dando início às Guerras Guaraníticas. Tal fato, aliado às duras críticas durante o século XVIII a atuação da Companhia de Jesus na Europa, época do Absolutismo e do Iluminismo, permitiu que ocorresse a expulsão dos padres jesuítas da Espanha e de suas colônias pelo decreto do Rei Carlos III, de 27 de fevereiro de 1767 (cf. Kern, 1990). $\mathrm{Na}$ América, a expulsão se deu no ano seguinte. As mudanças introduzidas na vida dos povos guaranis depois da expulsão dos jesuítas alteraram de tal maneira sua essência que, com razão, se tem dito que as reduções enquanto tais deixaram de existir.

Atualmente, essas reduções com suas igrejas majestosas se encontram em ruínas. As degradações deste patrimônio cultural transformado em ruínas foram provocadas por diversos fatores. Algumas foram destruídas devido às guerras constantes, seja pelos atritos bélicos entre portugueses e espanhóis ou pela afirmação dos Estados Nacionais nascentes. Outras foram abandonadas pelos seus antigos moradores. A força da natureza, com o avanço da vegetação, a ação das chuvas e a presença de insetos provocaram grandes danificações. A ação humana, através da reutilização das pedras em novas construções, a ação dos caçadores de tesouro, os atos de vandalismo e o descaso das autoridades responsáveis, contribuíram de forma decisiva para o desastre. Sem contar o próprio sistema construtivo empregado nessas edificações. Essas ruínas estão mais isoladas e distantes uma das outras hoje do que na época da experiência reducional.

Transformadas em Patrimônio Cultural da Humanidade pela UNESCO, em 1983, essas ruínas são visitadas por milhares de pessoas anualmente. São Miguel das Missões, do lado brasileiro, ostenta esse título e tornou-se uma das ruínas mais imponentes do que já foram um dia as Reduções Jesuíticas dos Guaranis. Neste sítio encontramos a fachada da igreja de Gian Battista Primoli, obra vultosa e de destaque dentro da arquitetura missioneira, algumas residências indígenas, resquícios do colégio e de outros elementos urbanos e arquitetonicos, além do principal museu público de imagens missioneiras: o Museu das Missões. 


\section{Museu das Missões}

O Museu das Missões foi criado pelo Decreto-Lei n ${ }^{\circ}$ 2077, de 08 de março de 1940, em plena Ditadura do Estado Novo. Quem o projetou foi o arquiteto Lúcio Costa, mais conhecido pelo projeto urbanístico de Brasília, realizado mais de vinte anos depois. Já naquela época, era um arquiteto respeitado. Conseguiu unir as arquiteturas missioneira e a espanhola em linguagem moderna, reutilizando materiais e formas na construção da Casa do Zelador e do Museu das Missões. As obras foram erigidas no canto da praça, formando um "L". O objetivo era servir de ponto de referência e dar uma idéia melhor das dimensões da praça (Pessoa, 1999, p. 39). O pequeno edifício é dividido por paredes paralelas de tijolos e argamassa, sendo que, ao seu redor, erguem-se paredes e portas de vidro, proporcionando claridade ao ambiente. Possui uma cobertura de quatro águas apoiadas em pilastras, formando um alpendre ao redor do edifício. Ele reúne cerca de 100 esculturas em madeira policromada, em sua maioria imagens de santos, de figuras que compunham cenas sacras ou de fragmentos de retábulos. Constitui-se na maior coleção pública missioneira, com peças que possuem desde alguns centímetros até imagens com mais de dois metros de altura, a maioria feita pelos guaranis. Nas esculturas, os traços indígenas são evidentes em algumas feições dos rostos, nos detalhes dos cabelos, vestes ou traçados. É o caso de uma estátua de Nossa Senhora da Conceição, representada visivelmente como uma indígena.

Desde o nosso primeiro contato com as Reduções Jesuíticas dos Guaranis, em 1996, já havíamos despertado a seguinte inquietação: o que levam as pessoas a visitar esse patrimônio cultural5? De fato, para se deslocar para um local longínquo, que ocupa um tempo grandioso para sua chegada e de custo muito alto, a pessoa deve estar mais do que predisposta. Por outro lado, qual é a recepção estética ${ }^{6}$ que proporciona um monumento histórico missioneiro nes-

\footnotetext{
5 Patrimônio histórico, artístico ou cultural? Durante décadas referiu-se ao patrimônio de um país como histórico e artístico. Atualmente, o patrimônio histórico e artístico é considerado conceitualmente como um segmento de um acervo maior chamado de Patrimônio Cultural. Ver LEMOS, 1981, pg. 8.

${ }^{6}$ Para esse estudo, entendemos a estética segundo os preceitos teóricos de Juan ACHA. O crítico de arte peruano retoma a origem da estética como sinônimo de gosto e utiliza a divisão materialista da cultura para reafirmar que a cultura estética pertence à cultura espiritual da humanidade, em relação dialética com a cultura material. Neste sentido, funcionaria como um enorme "guarda-chuva", que abarca toda as manifestações da consciência social dos membros de uma dada sociedade. Como o autor mesmo resume, "... lo estético es inevitable y cotidiano, espontáneo y orientado hacia las bellezas naturales o culturales, todas valorativas; por consiguiente, no existe hombre sin vida estética y ésta se centra, para nosotros, en la sensibilidad o gusto, una facultad humana ocupada en nuestros ideales de belleza y sentimientos dramáticos, cómicos, de sublimidad o tipicidad. En fin, lo estético se ocupa de nuestras preferencias y aversiones sensitivas o estéticas, gracias a las cuales mantenemos relaciones con la realidad inmediata y diaria” (“... o estético é inevitável e cotidiano, espontâneo e orientado para as belezas naturais ou culturais, todas valorativas; por conseqüência, não existe homem sem vida estética e esta se centra, para nós, na sensibilidade ou tipicidade. Enfim, o estético se ocupa
} 
te visitante? Um estudo de recepção estética nas reduções implica portanto em obter resposta quanto a esse impacto, verificar como ela atua no seu imaginário.

O trabalho que atualmente exercemos é investigar a recepção estética do monumento cultural missioneiro junto aos visitantes das ruínas das Reduções Jesuíticas dos Guaranis. São objeto de análise o sítio de São Miguel, que contempla as ruínas da Redução de São Miguel e o Museu das Missões, localizada no Rio Grande do Sul, Brasil. Aproveitamos para esclarecer que não separamos as obras que estão no Museu do conjunto do sítio, que formam o Patrimônio da Humanidade $n^{\circ} 63$ da Unesco. Elas fazem parte do Monumento Cultural, como prescreve a Carta de Veneza e outros documentos referentes a preservação do patrimônio.

\section{A recepção estética nos monumentos culturais missioneiros}

A recepção estética surgiu na aula inaugural da Universidade de Konstanz, na Alemanha, em 1968. O palestrante, o professor de literatura Hans Robert Jauss, a definiu pela primeira vez como a pesquisa sobre a recepção da literatura e seus efeitos no leitor, além de uma superação do formalismo russo e da teoria e crítica literária marxista. Nesta nova análise, os olhos da literatura estão na recepção do texto pelo leitor, introduzindo uma nova estética: a relação do autor com a obra dentro de um contexto dado (cf. Lima, 2002). Jauss propôs, como movimento, a análise da experiência do leitor ou da sociedade de leitores de um tempo histórico. Seu conterrâneo, Wolfgang Iser afirmou que o leitor, diante dos vazios do texto, deveria encontrar pontos de indeterminação que preencheria de acordo com o seu próprio imaginário.

$\mathrm{Na}$ história da arte, ela surge como uma provocação e desafio à análise da obra de arte, passando a entender a estética da recepção como "o tipo de indagação em torno da obra de arte que tematiza o receptor, o leitor, o observador como parte fundamental da práxis da arte; estética da recepção é o trabalbo de estudo teórico que indaga sobre o papel ativo deste integrante da práxis artística" (Gonçalves, 2001, pg. 89).

No nosso estudo, a recepção estética desloca-se do campo da literatura para o campo artístico-cultural, entendendo a estética com um sentido muito mais amplo do que o usual, devolvendo "... al término estético (aisthesis) su acepción original y real de percepción sensorial para, de aqui, derivar el derecho a identificarla con sensibilidad o sensorialidad, capacidad humana que es sinónimo de gusto"» (Acha, 1988,

\footnotetext{
de nossas preferências e aversões sensitivas ou estéticas, graças as quais mantemos relações com a realidade imediata e diária"). (1988, pg. 22).

${ }^{7}$ Definição baseada em LiMA (1997).

8 “... ao termo estético (aisthesis) sua concepção original e real de percepção sensorial para, daqui, derivar o direito a identificá-la com sensibilidade ou sensorialidade, capacidade humana que é sinônimo de gosto”).
} 
pg. 18). A partir deste sentido, o que pretendemos é a analisar a recepção estética das Reduções Jesuíticas dos Guaranis, enquanto monumento cultural, entendendo por monumento o que prescreve a Carta de Veneza ${ }^{9}$, especialmente no aspecto histórico que circunda esses monumentos culturais.

O que se pretende nessa pesquisa, que está em andamento, é analisar a recepção estética, no nível da sua percepção sensorial, pelos visitantes da principal ruína do que um dia foram as Reduções Jesuíticas dos Guaranis. Pretendemos buscar na nossa pesquisa se há mudanças significativas na recepção estética do monumento cultural missioneiro entre os visitantes de São Miguel das Missões, no Rio Grande do Sul.

Investigar como se dá, na atualidade, a recepção desses monumentos culturais pelos seus visitantes traz questões no campo da identidade cultural latino-americana. Será que a busca de uma identidade cultural nacional num monumento cultural tão distinto e singular, como as Reduções Jesuíticas dos Guaranis, pode vir a ser o fator principal nas variações de interpretação? Ou será a formação cultural que gera este fator? Aliás, existem essas variações de interpretação? Como os visitantes chegam a este sítio histórico-arqueológico? Devido ao turismo? Por razões místicas? Devido ao passado indígena? Devido a história dos jesuítas? Enfim, quais são os envolvimentos que o movem para realizar essa visitação? Como se configura a identidade cultural nacional com este monumento? É diferente ou semelhante em cada um dos países? Projeta uma idéia de América Latina com um passado histórico comum? Qual o impacto das obras escultóricas do Museu das Missões no visitante de São Miguel? É uma identidade meramente artística, no campo do barroco? Como funciona a representação do monumento no contexto da "memória" do cidadão visitante? Será que os turistas percebem que se trata de um Patrimônio da Humanidade? Sabem o que isso significa? Sabem que a maioria dos artistas era indígena? Percebem os traços guaranis neste monumento cultural? O que representa para eles as imagens de uma cultura que pode não ser necessariamente vinculada ao ser brasileiro? Isso é perceptível? Acham que essa identidade cultural é indígena? É católica ou tem outra fonte mística? É latino-americana ou nacional? O que buscam aqueles que visitam o único monumento cultural comum a três países?

\footnotetext{
${ }^{9}$ Elaborada e firmada, em 1964, por especialistas mundiais no assunto, este documento ressalta que “... a noção de monumento compreende não só a construção arquitetônica em si mesma. O monumento é inseparável do meio em que se encontra situado e, bem assim, do ambiente histórico do qual constitui testemunho. Reconbece-se, conseqüentemente, valor monumental tanto aos grandes conjuntos arquitetônicos, quanto às obras modestas que adquiriram, no decorrer do tempo, significação cultural e bumana. [...] Quer sejam urbanos ou rurais, os sítios que são testemunbos de determinada civilização, de algum acontecimento bistórico ou de uma evolução significativa, devem constituir objeto de cuidados especiais" (apud ANDRADE, 1987, p. 77), (Grifos nossos).
} 
Essa pesquisa aponta para a necessidade da realização de uma Pesquisa Qualitativa junto aos visitantes das Reduções Jesuíticas dos Guaranis e sua relação com este monumento cultural. Essa metodologia nos parece a que melhor lida com a interpretação das realidades sociais. Entre diversos pesquisadores, a Pesquisa Qualitativa é aceita como advinda das Ciências Humanas, em especial, da Antropologia. Podemos situar sua formalização enquanto método no início da década de 1920, com a adoção de uma abordagem mais focalizada. A partir da década de 1970 houve um crescente interesse por esse método, especialmente nas áreas que envolviam pesquisa de mercado. Para o nosso estudo, entendemos que a pesquisa qualitativa

“... não procura enumerar e/ ou medir os eventos estudados, nem emprega instrumental estatístico na análise dos dados. Parte de questões ou focos de interesses amplos, que vão se definindo na medida que o estudo se desenvolve. Envolve a obtenção de dados descritivos sobre pessoas, lugares e processos interativos pelo contato direto do pesquisador com a situação estudada, procurando compreender os fenômenos segundo a perspectiva dos sujeitos, ou seja, dos participantes da situação em estudo" (Godoy, 1995, p.58).

Entendendo que "na pesquisa social, estamos interessados na maneira como as pessoas espontaneamente se expressam e falam sobre o que é importante para elas e como elas pensam sobre suas ações e as dos outros" (Bauer et alli, 2002, pg. 21). Nas entrevistas estimularemos a narração do sujeito em torno de um fato ou fenômeno de um objeto determinado. Constitui-se num grande problema nesta metodologia induzir o pesquisado a refletir as opiniões e anseios do pesquisador. "O problema surge quando os entrevistados dizem o que pensam que o entrevistador gostaria de ouvir" alerta Bauer (et alli, 2002, pg. 21), o que será prontamente evitado durante a pesquisa.

Sociedade singular, as Reduções Jesuíticas dos Guaranis formam um tema dos mais intrigantes da História da América do Sul, cerceada por lendas e mitos, assim como por uma vasta bibliografia. Muito se escreveu sobre a sua História, Arquitetura, Sistema Político e Econômico. No campo das Artes e do Patrimônio, obras como as dos argentinos Bozidar Sustersic, Ramon Gutiérrez, Norberto Levington; dos paraguaios Tício Escobar e Josephina Plá; dos Brasileiros Luís Bolcato Custódio, Armindo Trevisan, Mabel Leal Vieira e Maria Inês Coutinho, deram uma grande contribuição para pensarmos a arte.

Mas sentimos a ausência nessas pesquisas de uma investigação sobre o papel do receptor nessa estética pouco divulgada, o Barroco Guarani, estilo surgido na transculturação entre os mestres europeus e os índios guaranis, ao longo de 150 anos. Ainda não conhecemos uma pesquisa que nos dê conta do que pensa e sente o visitante de São Miguel ou de qualquer outra redução do Cone Sul, em relação a essas ruínas. 
Neste sentido, essa pesquisa visa cobrir uma lacuna e talvez estejamos iniciando uma área de pesquisa nos estudos missioneiros, ao analisarmos a recepção estética de monumentos culturais. Trata-se também de um projeto transdisciplinar, que envolve principalmente as áreas de História, Arte e Turismo. A intenção é realizar uma pesquisa qualitativa junto aos visitantes do sítio de São Miguel (ruínas e o museu), no Rio Grande do Sul. Sobrevém daí a sua importância e, até onde sabemos, a sua originalidade.

João Batista Neto. Doutorado (cursando). Área: Artes. Linha de Pesquisa: História da Arte. Escola de Comunicação e Artes - Universidade de São Paulo. Professor Mestre. Área: América Latina. Linha de Pesquisa: Comunicação e Cultura. Programa de Pós-Graduação em Integração da América Latina. Universidade de São Paulo. Professor Especialista. Área: Ensino de História. FAFI-FACEPAL. Professor Especialista (cursando). Área: Museologia. Especialização: Estudos de Museus de Arte. Museu de arte contemporânea - Universidade de São Paulo.Bacharel. Curso de História. Universidade Estadual de Londrina 